\title{
COMMENTARY - THE NEED TO IMPLEMENT POPULATION BASED CERVICAL CANCER SCREENING IN LIMITED RESOURCE SETTINGS USING AIDED VISUAL INSPECTION OF THE CERVIX
}

\author{
* M.C. Ezeanochie, ** A.A. Adolor, ** A. Ogini \\ * Department of Obstetrics and Gynaecology, University of Benin Teaching Hospital, \\ PMB 1111, Benin City, Nigeria \\ **National Cancer Prevention Program Lagos.
}

\section{Correspondence:}

Department of Obstetrics and Gynaecology, University of Benin Teaching Hospital, PMB 1111, Benin City, Nigeria

\section{E-mail: ezemichael75@yahoo.com}

Globally, more than 500,000 new cases of cervical cancer are diagnosed annually with over $80 \%$ of these cases in developing countries ${ }^{1}$. In developed countries, the incidence and prevalence of cervical cancer has been declining due to accessible organized cervical cancer screening using conventional cytology (Pap smear) and treatment of precancers. Available published data shows that cervical cancer mortality has decreased by $70 \%$ over the past five decades in the United States following the introduction of pap smear. ${ }^{2}$ Similarly, in Finland, the incidence of cervical cancer has reduced by more than $80 \%$ since the introduction of an organized cytology based screening programme. ${ }^{3}$ In sub-Saharan African, it accounts for $22.2 \%$ of all cancers in women and it is also the most common cause of cancer death among women. ${ }^{4}$ Also, about $60-75 \%$ of women in sub-Saharan Africa who develop cervical cancer live in rural areas and have no access to cervical screening. ${ }^{5}$ Despite the successes recorded in cervical cancer control in developed countries, this scenario has not been replicated in developing countries. Perhaps, the peculiar circumstances in these under resourced settings with widespread poverty, weak health infrastructure and other basic challenges are important obstacles that have made organized cervical cancer screening based on Pap smear largely unsuccessful. Therefore, there may be a need to reevaluate the use of cytology as the primary tool for cervical cancer screening in limited resource settings.

The population of women in Nigeria over 15 years who are potentially at risk of developing cervical cancer is estimated at 40.43 million persons. ${ }^{6}$ Also, current estimates indicate that every year approximately 10,000 women are diagnosed with cervical cancer and 8000 die from the disease while about $23.7 \%$ of women in the general population are estimated to harbor cervical HPV (the causative agent for cervical cancer) infection at a given time. ${ }^{6}$ The disparity between cervical cancer morbidity and mortality in the developed nations and Nigeria may probably be due to lack of organized accessible cervical cancer screening, high level of competing health needs, wide spread poverty and inappropriate health seeking behaviour.

Cervical cancer prevention worldwide is based on screening 
women using conventional cytology (Pap smear). Pap smear screening was developed in the 1930s and named after the inventor, Dr. George Papanicolaou. Pap smear programs, also known as cytological screening programs, have achieved impressive results in reducing cervical cancer incidence and mortality in some developed countries. Indeed, it has been estimated that cervical cancer incidence can be reduced by as much as 90 percent where screening quality and coverage are high. ${ }^{7}$ For example, in Finland, a national cervical cancer screening program that was launched in 1963 decreased the cervical cancer rate to 5.5 cases per 100,000 women, a rate that is among the lowest in the world. ${ }^{8}$ In contrast to developing countries, where about 80 percent of all new cases exist, it has been estimated that only five percent of women have had a Pap smear in the last five years.'

Pap smear is a multistage process that involves sampling cells from the transitional zone of the cervix using either a wooden spatula or a brush. The cells are smeared on a glass slide and appropriately fixed while the slide is sent to a trained cytopathologist for review and detection of abnormality. This multistage process can take several weeks before the results are available to the client, although in wellorganized programs results can be available sooner. A promising cytology based method is the Liquid based cytology (LBC) which is more sensitive $(94.4 \%)$ than pap smears ${ }^{10}$ and has a potential to reduce the number of visits by clients for unsatisfactory smears and in addition provide specimen for HPV DNA testing. LBC is however more expensive than the Pap smear and requires technical laboratory support for successful implementation. This drawback is an important challenge to its widespread use in limited resource settings.

Published data revealed varying degrees of sensitivity and specificity for Pap smear when conducted at different settings. In a study conducted at Kenya, pap smear had a sensitivity and specificity of $83 \%$ and $94.6 \%$ respectively, 10 in another study in India, pap smear had a sensitivity and specificity of $53.7 \%$ and $50 \%$ respectively, ${ }^{11}$ while in another study carried out in rural Peru, pap smear had a sensitivity and specificity of $26 \%$ and $99 \%$ respectively. ${ }^{12}$ Therefore, a particular client may require more than one smear for a reliable diagnosis to be made before planning for treatment of premalignant lesions detected. This may reduce compliance of clients to screening programs especially as premalignant lesions are asymptomatic. Even when screening coverage is high, if premalignant lesions are not detected and properly managed, the overall objective of reducing new cases of cervical cancer may not be readily achievable. In Nigeria; a developing country, conventional Pap smear screening may not therefore be the ideal technology of choice for a successful population based screening program.

Recently, Visual Inspection Approach (VIA) using either 3-5\%

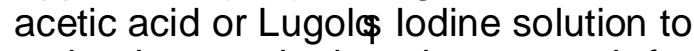
stain the cervix has been used for cervical cancer screening programs especially in developing countries. Visual inspection with acetic acid is a simple painless screening procedure that takes about 5minutes to perform. The Client is counseled on the procedure and an informed consent taken. With the client placed in a lithotomy position, a pelvic examination is done, and a $3-5 \%$ acetic acid or Vinegar solution is applied with a swab on stick within the 
transitional zone of her uterine cervix and result read after about a minute. The result could be normal if there is no color change or positive if a dense white color is noted within the area of application of the 3-5\% acetic acid. VIA have specificity and a sensitivity of $73.3 \%$ and $80.0 \%$ respectively. ${ }^{10}$ This is comparable to published data on conventional pap smears. The benefit of the visual approach over Pap smear is that the results are immediate and as a result treatment could be offered on the spot for precancerous lesions. The Single Visit Approach (SVA) involves offering cervical screening with Visual inspection method using either 3-5\% acetic acid or Lugols iodine and treatment offered to clients with noted precancerous lesions. The treatment offered an abnormal VIA screening is either an excision treatment or an ablative method using cryotherapy. Cryotherapy is a painless procedure which takes about $15-20$ minutes to perform; it is relatively inexpensive compared to other treatment modalities and is effective for premalignant lesions.

VIA can be performed by lower cadres of health personnel, does not require high tech expensive technology and infrastructure to perform, is very affordable, and provides almost the same result as the pap smear used in developed nations. In addition, it is has been observed in some studies that VIA reduces the percentage of women lost to follow up and the need for multiple visits to the health facility. ${ }^{13}$

However VIA is best suited for women whose transformation zone is still visible in the ecto-cervix during speculum examination. Hence, its use may be limited in screening postmenopausal women.

Recently, studies have demonstrated that HPV DNA test results are more sensitive than Pap smear in detecting high grade dysplasia in older women. ${ }^{14}, 15$ The direct detection of HPV in cervical specimen may therefore offer an alternative or complement to population based cytological screening. The advantages of HPV DNA testing over cytology are that it does not require the same level of technical expertise as cervical cytology; it is amenable to large scale population based screening and identifies women with current disease and those at risk of developing the disease over the next 2-3 years. Currently, HPV DNA testing is comparatively more expensive and may not be readily available or accessible in limited resource settings. It is expected that the cost of administering HPV DNA testing will reduce in future and the need for its use in limited resource settings in cervical cancer screening programmes may become more compelling.

In conclusion,because of the challenges associated with ensuring high quality cytology based services in limited resource setting, and with the high cost of conducting HPV DNA screening, an organized VIA approach may be a useful alternative to the conventional cytology and HPV DNA testing in screening for cervical cancer. It offers a comparatively cheaper screening platform with minimal manpower requirements. In addition, the problem of boss to follow upô associated with cytology based screening can be avoided with a single visit ścreen and treatômodel thereby offering treatment for screen positive persons. However, there may be still be a role for cytology based screening in focal communities where there is availability of the required man power and a motivated client base. This approach may be the most appropriate in limited resource settings in the short to medium term pending the increased accessibility and affordability of newer techniques such as HPV DNA testing. 


\section{References}

1. The American cancer society global cancer facts and figures 2007

2. American Cancer Society Guideline for the Early Detection of Cervical Neoplasia and Cancer

3. Strengthening cervical cancer prevention in Europe: Meeting of policy-makers and programme managers Copenhagen, Denmark, 29-31 May 2007

4. Parkin DM, Ferlay J, HAmdi-Cherif $M$, et al. Cancer in Africa: Epidemiology and Prevention. IARC scientific Publications. NO 153. Lyon: IARC press, 2003.

5. Parkin DM, Whelan SL, Ferlay J, et al.editors, Cancer incidence in five continents, Vol VIII, IARC Scientific Publication No. 155. Lyon:IARC, 2002.

6. Nigeria: Human Papiloma Virus and related cancers fact sheet, WHO/ICO information center on HPV and cervical cancer 2009.

7. Eddy DM. Secondary prevention of cancer: an overview. Bulletin of the World Health Organization 64(3):421ï 428 (1986).

8. Hakama $M$, Joutsenlahti $U$, Virtanen A, et al. Mass screenings for cervical cancer in Finland 1963ï 71. Organization, extent, and epidemiological implications. Annals of Clinical Research 7:101ï 111 (April 1975).

9. Planning Appropriate cervical cancer prevention $2^{\text {nd }}$ edition 2000. $\mathrm{Pg} 11$

10. H. De Vuyst, P. Claeys, S. Njiru, L. Muchiri, S. Steyaert, P. De Sutter, E. Van Marck, J. Bwayo, M. Temmerman. Comparison of pap smear, visual inspection with acetic acid, human papillomavirus DNAPCR testing and cervicography International Journal of Gynecology \& Obstetrics - May 2005 (Vol. 89, Issue 2, Pages 120-126, DOl: 10.1016/j.ijgo.2005.01.035)

11. Sherwani RK, Khan T, Akhtar K, Zeba A, Siddiqui FA, Rahman K, Afsan N. Conventional Pap smear and liquid based cytology for cervical cancer screening - a comparative study. J Cytol 2007;24:167-72

12. AlmonteMet al., Cervical screening by visual inspection,HPV testing,Liquid-based and conventional cytology in Amazonian Peru, International Journal of Cancer, 2007, 121(4):796ï 802.

13. 13.Jeronimo J, Morales O, Horna J, Pariona J, Manrique J, Rubiños J, Takahashi R. Visual inspection with acetic acid for cervical cancer screening outside of low-resource settings. Rev Panam Salud Publica. 2005;17(1):1ї 5.

14. Marie-Hélène Mayrand, M.D., Eliane Duarte-Franco, M.D., Isabel Rodrigues, M.D., Stephen D. Walter, Ph.D., James Hanley, Ph.D., Alex Ferenczy, M.D., Sam Ratnam, Ph.D., François Coutlée, M.D., and Eduardo L. Franco, Human Papillomavirus DNA versus Papanicolaou Screening Tests for Cervical Cancer. N Engl J Med 2007; 357:1579-1588.

15. Gravitt PE, Paul P, Katki $H A$, Vendantham $H$, Ramakrishna G, et al. 2010 Effectiveness of VIA, Pap, and HPV DNA Testing in a Cervical Cancer Screening Program in a Peri-Urban Community in Andhra Pradesh, India. PLoS ONE 5(10): e13711. doi: 10.1371/journal.pone.0013711 